\title{
Management of self-inflicted orchiectomy in psychiatric patient. Case report and non-systematic review of the literature
}

\author{
Marco Garofalo ${ }^{1}$, Alessandro Colella ${ }^{1}$, Paolo Sadini ${ }^{1}$, Lorenzo Bianchi ${ }^{1}$, Giacomo Saraceni ${ }^{2}$, \\ Eugenio Brunocilla $^{1}$, Giorgio Gentile ${ }^{3}$, Fulvio Colombo ${ }^{3}$ \\ ${ }^{1}$ Department of Urology, Sant'Orsola Hospital - University of Bologna, Bologna, Italy; \\ ${ }^{2}$ Complex Pelvic Surgery Unit, Department of Gynecology and Urology, Sant'Orsola-Malpighi Hospital, Bologna, Italy; \\ ${ }^{3}$ Andrology-Unit, Sant'Orsola Hospital - University of Bologna, Department of Gynecology and Urology, Bologna, Italy.
}

\begin{abstract}
Summary Introduction: Self-inflicted orchidectomy and auto-castration, also known as "Eshmun complex" is a rare phenomenon. The aim of our study it to present the management of a patient who performed a self orchiectomy and propose a non-systematic review of literature about self-orchiectomy.

Material and method: A 27-years old male Patient with psychiatric disorder was admitted to our ward to have been cutted his scrotum with scissors and cut away his left testicle causing active bleeding from the left spermatic artery. The patient underwent emergency surgery with clamping of the spermatic cord and hemostasis of the wound.

Results: After surgery the clinical condition of the patient remained good during whole hospitalization. Urgent psychiatric evaluation was performed in order to administer proper therapy for acute management. To best of our knowledge, only 11 cases of self-orchidectomy are reported in literature and all of them except 1 case, underwent surgical exploration.

Conclusions: Self-orchidectomy is an extremely rare phenomenon, often associated with psychiatric disorders, compounded by the use of drugs. In our opinion, emergency surgery should be the first choice of treatment, offering diagnostic and hemostatic purpose in a single act, aimed to prevent acute and postacute complications.
\end{abstract}

KEY WORDS: Self orchiectomy; Genital mutilation; Self castration. Submitted 15 May 2018; Accepted 26 July 2018

\section{INTRODUCTION}

Self-inflicted testicular injury is a rare phenomenon, with less than 200 cases reported in literature (1). Scrotal traumas are included in a different genital self-mutilation (GSM) setting, with lesions varying from tissues laceration to ablation of the whole external genitals (2). Most self-inflicted testicular injuries have been reported in trans-sexual patients who desire emasculation (3) or by psychotic patients with either functional or organic brain disease $(4,5)$.

Self-inflicted orchidectomy and auto-castration, also known as "Eshmun complex" $(6,7)$ is a type of major-selfmutilation (MSM) common among young individuals affected by psychiatric disorders, especially during acute psychotic state (1). This traumatic injury is less common in delusional and depressed individuals or in subject with no mental illness history $(8,9)$. Risk factors for GSM include: commanding hallucinations, religious delusions, substance abuse and social isolation $(5,10,11)$.

It has been reported a correlation between schizophrenia (or its acute state induced/flared by drugs abuse and acute psychotic states induced by recreational drugs consumption) and major self-mutilations (12, 13); sometimes genital mutilation can also be the presenting sign of schizophrenia (14). Auto-castration in a setting of drugs abuse alone, especially of a single drug (mainly methamphetamine and cannabinoids) and within absence of a certified mental illness history, has also been described (15-17). The vast majority of reported cases have occurred among single, white males in their 20s and 30s (18).

Usually, patients report all the common signs in traumatic amputation of the testis (namely, exposed lacerated wound, avulsion, etc). In addition, very few other cases show genital auto-mutilation of one or both testicles without involving the penile shaft. We show a case of unilateral self-orchidectomy performed in a "surgical fashion", resulting in a closed wound acute scrotum presentation. The aim of our study it to present the management of a patient who performed a self-orchiectomy; we also propose a non-systematic review of literature about self-orchiectomy.

\section{MATERIALS AND METHOdS}

21.03.2017. 03:12 p.m. A 27-years old male Patient, voluntarily admitted to St. Orsola Malpighi Hospital's Casualty Ward, asking for medical assistance for referred "scrotal bleeding and self-orchidectomy". Patient was already admitted before, since he was followed by a psychiatric clinic due to schizophrenia, not properly adherent to Fluphenazine prescription. The patient lucidly reported his psychiatric disorder at beginning of medical consultation and he reported that he incised his scrotum with scissors and cut away his left testicle, then he sutured his scrotum by himself. He had no mention of local anesthesia or analgesic usage.

Genital examination revealed globally swollen and round scrotum (approximately $15 \mathrm{~cm}$ ). Scrotal skin, looking stretched, dehydrated and clean, was involved by a large 
Figure 1.

Preoperative picture of the scrotum, with the surgical suture made by the patient.

A.
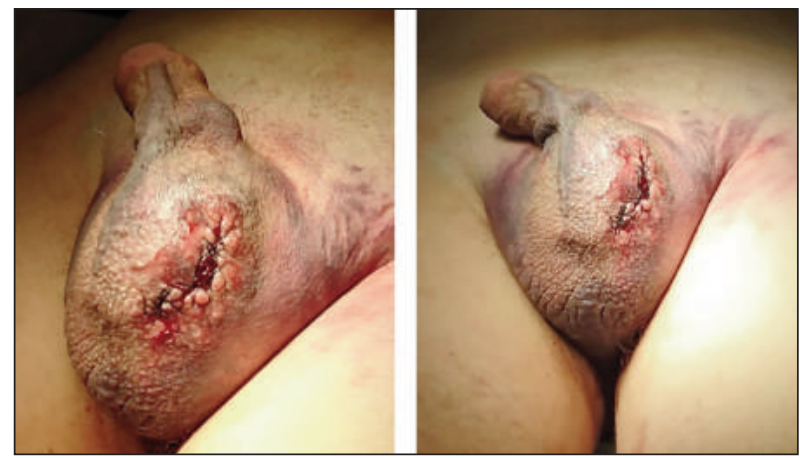

Figure 2.

Ultrasound of scrotum: a) right scrotum with regular right testis b) left scrotum, without the testis.

A.
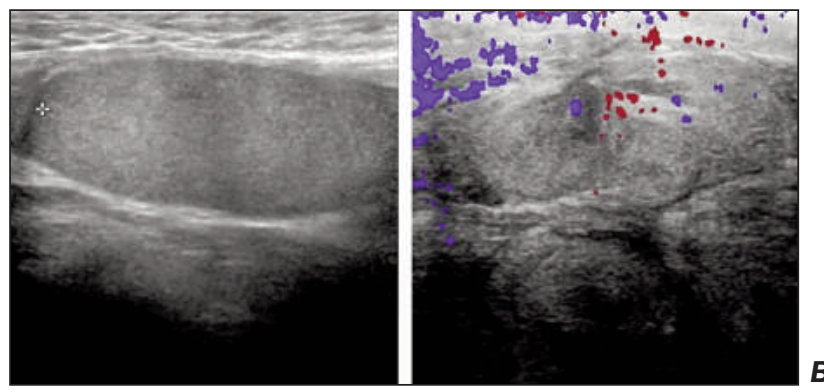

Figure 3.

Intraoperative picture: the cut funiculus.

A.
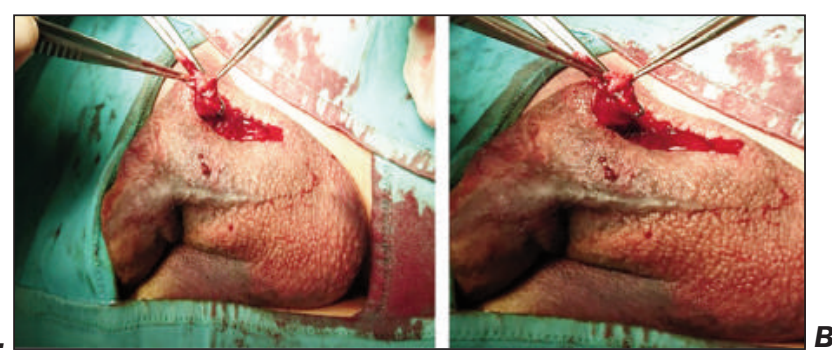

ecchymosis more evident on the lower-left side. Indeed, on the left side, at lower-middle third, a cutaneous suturing measuring approximately $1 \times 0.5 \mathrm{~cm}$ appeared as repaired by suturing stitches made of common cotton thread (Figures la, 1b).

Ultrasound evaluation by scrotal eco-color-Doppler (ECD) has been performed, according to the casualty ward's dedicated acute scrotum diagnostic protocol. The ECD showed a normal, despite dislocated, right testicle (Figure $2 \mathrm{a}$ ) and an extensive hematoma of the left scrotum cavity with a modest color-Doppler signal within its content, but no evaluable left testicle (Figure 2b).

Blood exams were indicative for acute infection and inflammation (White blood cells: 19.01 x 10^9/L; Neutrophils: 16.13 x 10^9/L); toxicological screening found high amounts of plasmatic cannabinoids (69 $\mathrm{ng} / \mathrm{mL}$ ). Total hemoglobin was $13.8 \mathrm{~g} / \mathrm{dL}$. within normality ranges of Hematocrit and Red Blood Cells total amount.
Basing on this preliminary data, in absence of major bleeding, considering the regular Glasgow Coma Scale (GCS) and mental status, himself showing a calm and cooperative behavior, we aimed firstly to determine the entity of lesion, the extent of active bleeding and the need of acute management by surgical exploration.

Examination was extended through palpation and manipulation of external genitals, revealing a scrotal fistula covered by uneven wire stitching on the left scrotal sack. By applying progressive non-traumatic digital pressure, the left scrotum was evacuated from an approximate amount of $400 \mathrm{ml}$ of blood clots and serous/hematic material through the un-sutured scrotal breech.

This maneuver allowed palpation of scrotal content. B. Therefore, surgical scrotal exploration was planned in emergency, with the consent of the informed patient.

Antibiotic prophylaxis was administered by endovenous infusion of cefuroxime 2 gr. First, we removed some black cotton double-wired single-suturing stitches overlapping each other in the left scrotum, assumed to be placed with a sewing needle. So, an irregular circular area of excision of $4 \mathrm{~cm}$ involving all scrotal wall tissues, appeared. Scrotal incision margins presented as neat as a single or few scissor section lines. Evacuation of approximately $100 \mathrm{ml}$ of blood clots revealed an empty left hemiscrotum. An active bleeding sprouting was individuated from the left spermatic artery; this revealed the distal portion of the left spermatic chord (Figures 3a, 3b), suggesting that the spermatic chord incision has been conducted by the patient above the testicular veins; no testicular or epididimal remnants were found. Didymus and epididymis were missing: in fact, the patients referred in follows consultation, that he threw the testis into the toilet.

After clamping and dissection of distal amputated spermatic chord, the vessels and the vas deferens were sutured separately with 2-0 Vicryl ${ }^{\circledR}$. After washing the cavity, the hemostasis check showed no further bleeding and no other trauma. A percutaneous suction drainage has been placed in the left scrotal cavity. Finally, the scrotum has been repaired by suturing the Dartoic plane and the skin in 4-0 SafilQuick ${ }^{\circledR}$ absorbable single stitches.

\section{Results}

After surgery, the clinical condition of the patient remained good during whole hospitalization. Intravenous fluids, anti-inflammatory drugs and analgesic have been administered. The day after the surgical intervention, the vital signs were good and stable; Hemoglobin values of $11.0 \mathrm{~g} / \mathrm{dL}$ in the first postoperative day, lined with the blood loss before the hemostasis in the operating theatre (Estimating Blood Loss: $150 \mathrm{cc}$ ) and the inflammation signs were considerably reduced (White Blood Cells $8.92 \times 10^{\wedge} 9 / \mathrm{L}$ ).

There was no fever, no local or systemic infection and good status of the surgical wound.

Urgent psychiatric evaluation was performed in order to administer proper therapy for acute management.

The patient referred during the Psychiatric evaluation that his act was impelled by voices inside his head, and probably this escalated quickly with chronic and acute abuse of cannabinoids. Moreover, he said that he felt no pain during the mutilation. Since the surgical postopera- 
Table 1.

Review of literature on penile trauma and anterior urethral rupture: characteristic of studies, population and management.

\begin{tabular}{|c|c|c|c|c|c|c|}
\hline Authors & Study & Years & $\begin{array}{l}\mathrm{N}^{\circ} \text { patients } \\
\text { (total) }\end{array}$ & $\begin{array}{l}\text { Psychiatric/neurologic } \\
\text { pathology }\end{array}$ & Drugs & Management \\
\hline Sutchin R. Patel et al. & Case report & 2007 & 1 & $\begin{array}{l}\text { Gerstmann-Straüssler-Scheinker } \\
\text { syndrome }\end{array}$ & - & Surgery \\
\hline Helen Stunell et al. & Case report & 2006 & 1 & Paranoid schizophrenia & - & Surgery \\
\hline Ugur LoK et al. & Case report & 2014 & 1 & Unknown & - & Surgery \\
\hline A.A. Ajape et al. & Case report & 2010 & 1 & Depression & - & Surgery \\
\hline$\overline{\text { Moudif K. et al. }}$ & Case report & 2004 & 1 & Unknown & Unknown & Surgery \\
\hline Wade C. Myers M.D., et al. & Case report & 2001 & 1 & Schizophrenia & - & Conserevative/medical \\
\hline Eugene F. Simopoulos, M.D., et al. & Case report & 2012 & 1 & $\begin{array}{c}\text { Major depression, } \\
\text { Social anxiety disorder, } \\
\text { gender identity disorder, } \\
\text { and complex } \\
\text { Post-traumatic stress disorder }\end{array}$ & Lorazepam, ramelteon & Surgery \\
\hline Abdurakhmanov RA, et al. & Case report & 2016 & 1 & Unknown & Unknown & Surgery \\
\hline$\overline{\text { Rehan Ahmed Siddiquee, et al. }}$ & Case report & 2007 & 1 & Schizophrenia & - & Surgery \\
\hline Jacek S. Anand et al. & Case report & 2014 & 1 & $\begin{array}{c}\text { Polydrug abuse } \\
\text { Borderline personality disorder }\end{array}$ & $\begin{array}{l}\text { Methamphetamine } \\
\text { (up to } 500 \text { mg per day) }\end{array}$ & Surgery \\
\hline Mustapha Ahsaini & Case report & 2011 & 1 & Cannabis abuse & Cannabinoids & Surgery \\
\hline$\overline{\text { TOTAL }}$ & & 11 & 160 & & & \\
\hline
\end{tabular}

tive convalescence elapsed without complication, the patient was transferred to a psychiatric ward.

\section{Discussion}

GSM is a rare phenomenon. The most common self-mutilating behavior is cutting one's own wrist, which is usually committed by adolescents or by the mentally retarded for attention-seeking purposes. Rarely, self-mutilation has a serious scenario that leads the patient to attempt to amputate his penis, to castrate himself, to extract his eye or to amputate his hand (19). The instruments that have been used include kitchen knives, blades, scissors, a chainsaw and an axe. Most of cases reported in the literature, consist of patients with psychosis or psychiatric disorders with either functional or organic brain disease. Such cases have been observed in schizophrenia or depression, and it is sometimes difficult to diagnose these conditions because such a behavior is usually the only presenting symptom of the psychiatric disorder. However, few cases have been described in non-psychotic persons. It has been suggested that there is no difference in the severity of the self-inflicted injuries between psychotic and non-psychotic patients. In our case report, the reason for self-mutilation of the testis was the status of schizophrenia compounded by the use of drugs.

As the degree of mutilation varies, so does the treatment, which can be complex and quite challenging; it often consists of a multidisciplinary management between the urologist, psychiatrist, psychologist and primary care physician. Early diagnosis and fast treatment can reduce the acute and post-acute complications (blood loss, infections, hemorrhagic shock...). To best of our knowledge, only 11 cases of self-orchidectomy are reported in literature and all of them except 1 case, underwent surgical exploration (Table 1).
The main goal of surgical treatment includes restoration of the anatomy and function of mutilated organs, as much as possible. A superficial laceration may require no more than simple suturing; a serious injury with selfmutilation of organ or part of it, as we reported in the present case report, needs an emergency intervention. Complications resulting from GSM vary according to the severity of the injury inflicted and the extent of surgical repair undertaken.

\section{Conclusions}

Self-orchidectomy is an extremely rare phenomenon, often associated with psychiatric disorders, compounded by the use of drugs. In our opinion, emergency surgery should be the first choice of treatment, offering diagnostic and hemostatic purpose in a single act, aimed to prevent acute and post-acute complications. However, a multidisciplinary approach is essential and includes a careful psychiatric evaluation to avoid recurrences and to more extensively support these patients through their mental and physical integrity recovery.

\section{REFERENCES}

1. Veeder TA, Leo RJ. Male genital self-mutilation: a systematic review of psychiatric disorders and psychosocial factors. Gen Hosp Psychiatry. 2017; 44:43-50.

2. Stunell H, Power RE, Floyd M, Quinlan DM Genital self-mutilation. Int J Urol. 2006; 13:1358-60.

3. Simopoulos EF, Trinidad AC. Two cases of male genital self-mutilation: an examination of liaison dynamics. Psychosomatics. 2012; 53:178-80.

4. Patel SR, Thavaseelan S, Handel LN, et al. Bilateral manual 
externalization of testis with self-castration in patient with prion disease. Urology. 2007; 70:590.e15-6.

5. Ozan E, Deveci E, Oral M, et al. Male genital self-mutilation as a psychotic solution. Isr J Psychiatry Relat Sci. 2010; 47:297-303.

6. Kushner AW. Two cases of auto-castration due to religious delusions. Br J Med Psychol. 1967; 40:293-8.

7. Eke N. Genital self-mutilation: there is no method in this madness. BJU Int. 2000; 85:295-298.

8. Ajape AA, Issa BA, Buhari OI, et al. Genital self-mutilation. Ann Afr Med. 2010; 9:31-4.

9. Mareko GM, Othieno CJ, Kuria MW, et al. Body dysmorphic disorder: case report. East Afr Med J. 2007; 84:450-2.

10. Rao KN, Bharathi G, Chate S. Genital self-mutilation in depression: a case report. Indian J Psychiatry. 2002; 44:297-300.

11. Charan SH, Reddy CM. Genital self mutilation in alcohol withdrawal state complicated with delirium. Indian J Psychol Med. 2011; 33:188-90.

12. Vender S, Bianchi L, Callegari C, et al. Cannabis use and gen- ital self-mutilation: an update of case reports. Riv Psichiatr. 2015; 50:148-50.

13. Siddiquee RA, Deshpande S. A case of genital self-mutilation in a patient with psychosis. Ger J Psychiatry. 2007; 10:25-8.

14. Myers WC, Nguyen M. Autocastration as a presenting sign of incipient schizophrenia. Psychiatr. Serv. 2001; 52:685-6.

15. Ahsaini M, Tazi F, Khalouk A, et al. Bilateral testicular self-castration due to cannabis abuse: a case report. J Med Case Rep. 2011; 5:404

16. Anand JS, Habrat B, Barwina M, Waldman W. Repeated self-mutilation of testicles in the context of methamphetamine use e A case report and brief review of literature. J Forensic Leg Med. 2015; 30:1-3.

17. Large M, Babidge N, Andrews D, et al. Major self-mutilation in the first episode of psychosis. Schizophr Bull. 2009; 35:1012-21.

18. Lok U, Gulacti U, Benlioglu C, et al. Self mutilation of genitaliausing teeth. J Clin Diagn Res. 2014; 8:179-80.

19. Nerli RB, Ravish IR, Amarkhed SS, Manoranjan UD, Prabha V, Koura A. Genital self-mutilation in nonpsychotic heterosexual males: Case report of two cases. Indian J. Psychiatry 2008;50:285-7

\section{Correspondence}

Marco Garofalo, MD

marco.garofalo@unibo.it

Alessandro Colella, MD

alessandro.colella@studio.unibo.it

Paolo Sadini, MD

sadini@libero.it

Lorenzo Bianchi, MD

lorenzo.bianchi3@gmail.com

Eugenio Brunocilla, MD

eugenio.brunocilla@unibo.it

Department of Urology, Sant'Orsola Hospital - University of Bologna,

Bologna, Italy

Giacomo Saraceni, MD

giacomo.sareceni@libero.it

Complex Pelvic Surgery Unit, Department of Gynecology and Urology,

Sant'Orsola-Malpighi Hospital, Bologna, Italy

Giorgio Gentile, MD (Corresponding Author)

dr.giorgio.gentile@gmail.com

Fulvio Colombo, MD

fulvio.colombo@aosp.bo.it

Andrology-Unit, Sant'Orsola Hospital - University of Bologna,

Department of Gynecology and Urology, Bologna, Italy 